\title{
A RELEVÂNCIA DO TREINAMENTO DE HABILIDADES NÃO TÉCNICAS NA ATUAÇÃO DE PILOTOS DE AVIÃO
}

\section{ARTIGO ORIGINAL}

ACOSTA, João Pedro Lima ${ }^{1}$, COSTA, Nagi Hanna Salm ${ }^{2}$

ACOSTA, João Pedro Lima. COSTA, Nagi Hanna Salm. A Relevância Do Treinamento De Habilidades Não Técnicas Na Atuação De Pilotos De Avião. Revista Científica Multidisciplinar Núcleo do Conhecimento. Ano 06, Ed. 05, Vol. 10, pp. 57-76. Maio de 2021. ISSN: 2448-0959, Link de acesso: https://www.nucleodoconhecimento.com.br/ciencias-aeronauticas/pilotos-deaviao, DOI: 10.32749/nucleodoconhecimento.com.br/ciencias-aeronauticas/pilotosde-aviao

\section{RESUMO}

Historicamente, a formação de pilotos de avião foi, de modo predominante, voltada ao treinamento e desenvolvimento de habilidades técnicas, isto é, aquelas ligadas a aspectos como o controle da aeronave, o conhecimento de sistemas e motores e a navegação aérea. Com o advento de aeronaves comerciais cada vez mais automatizadas, os pilotos passaram a desempenhar também uma nova função, a de gerenciadores de sistemas automatizados. Por certo, a automação aumentou a segurança das operações aéreas devido à diminuição de falhas técnicas relacionadas à integridade da aeronave. Contudo, acidentes e incidentes aeronáuticos ainda ocorrem, tendo agora como principal fator contribuinte o aspecto humano e operacional. Logo, identificou-se a necessidade de melhorar o treinamento desses pilotos sob a ótica das habilidades não técnicas. Considerado esse cenário, o presente estudo foi realizado com o objetivo de elucidar a importância do desenvolvimento de habilidades não técnicas na atuação dos pilotos de avião. Tais habilidades são mais

\footnotetext{
${ }^{1}$ Graduação em andamento em Ciências Aeronáuticas.

${ }^{2}$ Orientadora. Doutorado em Ciências do Comportamento.
} 
comumente ensinadas por meio de treinamentos como o Crew Resource Management (CRM), o Line Oriented Flight Training (LOFT), o Treinamento de Habilidades Sociais (THS), o Multi-Crew Pilot License (MPL) e o Competency-Based Training (EBT), bem como identificadas pelo sistema NOTECHS. O propósito desses treinamentos é ensinar e desenvolver habilidades como comunicação e gerenciamento de recursos de cabine, atitude, julgamento, tomada de decisão, assim como o manejo de respostas emocionais e de fatores estressores. No entanto, tais treinamentos aqui citados ainda são de difícil acesso no mundo, principalmente no Brasil, então, é necessário que as agências reguladoras criem normas que implementem esses treinamentos nas instituições de ensino, para que no futuro tenhase uma diminuição do fator humano como contribuinte das ocorrências aeronáuticas através de um correto treinamento e atuação dos profissionais.

Palavras-chave: Habilidades Técnicas e Não Técnicas em Pilotos, Treinamento de Pilotos, Formação de Pilotos de Avião, Fator Humano na Aviação, Segurança Operacional.

\section{INTRODUÇÃO}

Desde os primórdios da aviação busca-se treinar e desenvolver habilidades nos pilotos, o que marcadamente teve início com o advento das duas grandes guerras mundiais e com o desenvolvimento da aviação na França. Contudo, essas habilidades ainda eram exclusivamente voltadas ao aperfeiçoamento de habilidades motoras, pois as aeronaves ainda não dispunham de sistemas automatizados de controle de voo.

Com a evolução das tecnologias, viu-se, cada vez mais, o desenvolvimento de aeronaves comerciais com sistema de controle de voo e sistemas automatizados. Com isso, o papel desempenhado pelo piloto e a sua atuação dentro da cabine mudaram, passando ele a ser também um gerenciador desses sistemas. Desse modo, percebeu-se a necessidade de treinamento e desenvolvimento de novas habilidades nos pilotos, as habilidades não técnicas, relacionadas ao desempenho humano, principalmente frente a situações adversas, uma vez que os fatores humanos e 
operacionais estão presentes na grande maioria dos acidentes e incidentes aeronáuticos na atualidade.

Contudo, a formação e o treinamento de pilotos no cenário mundial ainda são preponderantemente voltados ao desenvolvimento de habilidades técnicas ou motoras dos indivíduos. Vê-se, principalmente no Brasil, uma escassez de treinamentos que visem o desenvolvimento de habilidades não técnicas, seja nas escolas de aviação ou nas instituições de ensino superior que formam pilotos profissionais.

A temática demanda discussão mais aprofundada por parte das autoridades aeronáuticas e dos órgãos reguladores no Brasil e no mundo, visto que o cerne da aviação é o gerenciamento da segurança operacional e o seu aprimoramento. Por certo, o treinamento e o desenvolvimento de habilidades não técnicas nos profissionais que atuam no setor melhoram a relação homem-máquina, sendo indispensáveis no processo de gerenciamento de risco e mitigação do perigo na aviação, elevando, assim, os padrões de segurança operacional.

Nesse sentido, esse estudo tem por objetivo mostrar a relevância do treinamento de habilidades não técnicas em pilotos de avião com vistas ao melhor desempenho de suas funções e, especificamente, elucidar as habilidades técnicas e não técnicas tidas como indispensáveis. Visa ainda, apresentar os treinamentos disponíveis que têm como objetivo o desenvolvimento de repertórios comportamentais para o incremento e aprimoramento da performance desses profissionais.

A metodologia empregada revisa a literatura sobre o tema em manuais e normas que tratam da formação tradicional e os novos tipos de formação de pilotos, em vigor tanto no âmbito nacional quanto no internacional. Artigos e revistas científicas que tratam da temática e livros pertencentes à área de recursos humanos e de desenvolvimento de pessoal também compuseram a pesquisa bibliográfica e documental realizada. 
Estruturalmente, a pesquisa está disposta em cinco seções. A primeira corresponde a um breve histórico da aviação e do treinamento de pilotos. A segunda seção trata do conceito de segurança operacional e da prevenção de ocorrências aeronáuticas, e mostra dados do fator humano como fator contribuinte para acidentes aeronáuticos. A terceira discorre sobre a importância dos treinamentos de recursos humanos, de um modo geral. A quarta seção, por sua vez, expõe as novas habilidades requeridas dos pilotos no cenário atual da aviação. Ao final, são apresentados os treinamentos disponíveis no mercado que visam desenvolver habilidades não técnicas.

\section{BREVE HISTÓRICO DA AVIAÇÃO E DA FORMAÇÃO DE PILOTOS}

O sonho de alçar voos já era identificado na mitologia grega com a história de Dédalo e Ícaro, que tentaram deixar o labirinto de Creta voando com asas por eles construídas (KAPERAVICZUS; CAVENAGHI, 2018). Do mito à realidade, a história da aviação data do século 15, com os esboços de Leonardo Da Vinci, que realizou estudos sobre o funcionamento das asas dos pássaros e chegou a calcular a área de sustentação necessária para elevar um homem (CORDEIRO, 2006). No século XIX, foram desenvolvidas tecnologias suficientes para se projetar e construir máquinas voadoras, possibilitando ao homem alçar voos (PORTO, 2015).

No século $X X$, os irmãos americanos Wilbur e Orville Wright foram os pioneiros na realização um voo de um equipamento mais pesado que o ar, o Flyer, fato ocorrido em 17 de dezembro de 1903, nos Estados Unidos. Contudo, a máquina precisou de uma catapulta para se lançar ao ar por 12 segundos. Alguns anos depois, em 1906, o brasileiro Alberto Santos-Dumont fez história na cidade de Paris ao voar com o 14Bis, equipamento igualmente mais pesado que o ar, sem o auxílio de qualquer apoio, tendo voado por 7 segundos (CARNEIRO, 2016).

No âmbito da formação de pilotos dessas então novas máquinas que surgiam, o AéroClub de France tornou-se, em 1909, uma instituição pública com o intuito de delinear normas de segurança, estabelecer técnicas básicas de voo e expedir licenças de voo. No Brasil, a formação de pilotos é datada de 1911, quando foi criada no país a primeira 
escola de aviação civil, o Aeroclube Brasileiro, no Rio de Janeiro, visto como berço da aviação brasileira (PORTO, 2015).

A I Guerra Mundial (1914 - 1918) e a II Guerra Mundial (1939 - 1945) exerceram grande influência na história da aviação, principalmente na formação e no treinamento de pilotos. Segundo Barata e Neves (2017), o treinamento ocorreu, inicialmente, com a deflagração de ambas as guerras - em especial na segunda, quando o avião se tornou uma grande força bélica -, considerando a necessidade de se preparar um número significante de pilotos para o combate.

A partir da década de 1950, a formação e o treinamento de pilotos passaram por mudanças tremendas após o surgimento de aeronaves a jato. Assim, desenvolvia-se um novo período na aviação precedido da Convenção de Chicago, em 1944, que estabeleceu os primeiros padrões e práticas a estabelecidas pela Internacional Civil Aviation Organization (ICAO) como padrões mínimos para a concessão de licença de pessoal (ICAO, 2011).

A formação de pilotos civis era, a princípio, realizada em aeroclubes, que reuniam fãs e entusiastas da aviação que acabavam se tornando sócios do clube e, com isso, recebiam instrução, voavam e trocavam conhecimento, formando uma comunidade.

Nos períodos da II Guerra e do pós-guerra, houve um crescimento do número de pilotos brasileiros e estrangeiros no Brasil, o que evidenciou a falta de uma aviação mais abrangente no país, em especial, a aviação civil. Diante desse cenário, o Governo Vargas realizou a Campanha Nacional de Aviação (CNA), que angariava contribuições da sociedade para consolidar a aviação civil no país e, assim, possibilitar que os aeroclubes adquirissem aeronaves e materiais aeronáuticos e oferecessem treinamentos. Ademais, a CNA buscava, com a formação dos pilotos e constante movimentação no espaço aéreo brasileiro, em virtude da guerra, monitorar sobrevoos de aviões inimigos no território brasileiro. A CNA fez com que o número de aeroclubes no Brasil saltasse de menos de quarenta para cerca de quatrocentas instituições, 
aumentando, significativamente, de efeito, o número de pilotos no país (FAY; FONTES, 2016).

Com o passar dos anos, o treinamento de pilotos aperfeiçoou-se no Brasil e no mundo. Com o surgimento de aeronaves mais automatizadas na década de 80 , propiciado pelos avanços tecnológicos, o voo passou da necessidade do famoso "pé e mão" para um voo em que os pilotos cumprem também o papel de gerenciadores de sistemas computacionais. Tal fato estabeleceu uma nova relação homem-máquina, quebrando o paradigma da força física na pilotagem de aeronaves para impulsionar o desenvolvimento de habilidades de gerenciamento de voo e sistemas, submetendo os pilotos a um novo grau de conhecimento. O desenvolvimento de novas habilidades é, seguramente, uma necessidade crescente e constante no meio aéreo e na segurança de voo (RONDON; CAPANEMA; FONTES, 2014).

\section{A SEgURANCA OPERACIONAL E A PREVENÇÃO DE OCORRÊNCIAS AERONÁUTICAS}

De acordo com a ICAO (2013), a segurança operacional pode ser definida como um processo constante que visa a identificação de perigos e a gestão dos riscos associados às operações aéreas, para que a chance de lesionar pessoas ou ocasionar avarias em propriedades torne-se pequena e seja mantida em um nível aceitável ou abaixo deste.

Os acidentes registrados nos dias atuais, em sua maior parte, embora contenham aspectos técnicos, são, na verdade, mais relacionados aos organizacionais, englobando tanto fatores técnicos como os humanos. Por certo, a degradação da segurança operacional em uma estrutura de alta complexidade como a aviação não ocorre de forma linear, uma vez que existem mecanismos no interior da organização - entre eles as competências dos profissionais envolvidos - que exercem o papel de proteção, podendo conter, delimitar e temporizar o efeito adverso dessa degradação. Contudo, quando há falhas nesse mecanismo de proteção, tais lapsos podem 
desencadear eventos que acabam por resultar em acidentes ou incidentes aeronáuticos (CASSIANO, 2017).

Em vista disso, a existência desses recursos protetivos, que funcionam como barreiras que evitam ocorrências aeronáuticas, é de grande importância para as organizações e o sistema da aviação. Dentro desse contexto, destaca-se a necessidade de se observar, cuidadosamente, o modo como estão sendo formados e treinados os pilotos, para que lidem melhor com situações adversas vivenciadas no cotidiano da profissão, promovendo, assim, mais segurança para a operação (CASSIANO, 2017).

\subsection{ACIDENTES AERONÁUTICOS E O FATOR HUMANO}

A aviação é um sistema complexo e dinâmico. Frente às novas tecnologias embarcadas nas aeronaves e ao constante progresso do mercado e das práticas de segurança operacional e de prevenção de acidentes aeronáuticos, faz-se necessária a implementação obrigatória de treinamentos diversos, visando o contínuo desenvolvimento profissional daqueles que atuam no setor, em especial os pilotos (CASSIANO, 2017). Isso porque lacunas associadas a treinamento insatisfatório fazem com que os níveis de segurança operacional sejam reduzidos, sendo o fator humano apontado como contribuinte para $70 \%$ a $80 \%$ das ocorrências relacionadas ao transporte em aeronaves com mais de nove assentos e em aeronaves de carga no mundo (NTSB, 2010).

Conforme o Centro de Investigação e Prevenção de Acidentes Aeronáuticos (CENIPA, 2018), esses dados também podem ser percebidos no cenário brasileiro. Investigações realizadas e publicadas entre 2008 e 2017 indicam que aspectos relacionados ao desempenho humano - a saber, fator operacional e fator humano foram responsáveis por $66 \%$ e $34 \%$, respectivamente, dos fatores contribuintes para acidentes e incidentes aeronáuticos no Brasil, em detrimento dos aspectos técnicos ligados à aeronave, sua estrutura e sistemas. 
Entre os anos de 2010 e 2019, foram publicados 1.050 relatórios de acidentes ocorridos no Brasil, e observou-se que entre os 66 fatores contribuintes possíveis, a "instrução", que guarda relação com o fator operacional, esteve presente em $9,1 \%$ das ocorrências. Já na esfera dos fatores humanos, $6 \%$ dos casos envolveram falhas relativas à formação, à capacitação e ao treinamento de pilotos (CENIPA, 2020).

Esse cenário aponta a relevância do comportamento humano frente às operações aéreas e seu impacto na segurança operacional. Mesmo que novas tecnologias estejam sendo embarcadas nas aeronaves, reduzindo a chance do erro humano, algumas funções realizadas por humanos são insubstituíveis. Ademais, o homem tem uma notável participação na implementação e na busca pela melhoria da segurança operacional, ainda que com suas fragilidades e falhas. O elemento humano propicia, ainda, a flexibilidade e a adaptabilidade que um cenário complexo, como o da aviação, exige (REASON, 1990).

\section{O TREINAMENTO DE RECURSOS HUMANOS}

O treinamento de pessoas é visto como um processo que possibilita o desenvolvimento de importantes habilidades no seu convívio e na sua relação com o meio. No caso do ambiente de trabalho, sendo o da aviação um ambiente mais complexo, 'aprender' traduz-se em uma capacidade cada vez mais fundamental para assegurar o correto desempenho do profissional, principalmente frente a situações adversas. $\mathrm{Na}$ atualidade, o treinamento e o desenvolvimento de pessoas são peça fundamental no processo de evolução de uma organização ou sistema. Com efeito, os recursos humanos se constituem uma das maiores riquezas do sistema, mesmo diante de inúmeras inovações tecnológicas. Possíveis focos de problemas organizacionais e de baixo desempenho, que podem levar a consequências indesejáveis, advêm de uma possível falta de treinamento adequado (CHIAVENATO, 2020).

Para Milkovich e Boudreau (2010), o treinamento consiste em um processo estruturado com o objetivo de promover a aquisição de habilidades, regras e atitudes, 
ocasionando melhor adequação entre as particularidades dos colaboradores e as exigências de sua função. Reginatto (2004) argumenta que o treinamento auxilia as pessoas a serem mais eficientes, evitando erros, melhorando atitudes e alcançando maior produtividade, pois é por meio dele que se pode mudar comportamentos.

Já segundo Andrade e Castro (1996), o treinamento é entendido como o empenho da organização em possibilitar novas oportunidades de aprendizagem aos seus funcionários, para que estes criem novas habilidades e, por exemplo, possam adaptarse a alguma circunstância ou aprender o uso de novas tecnologias e sistemas. Chiavenato (2020), por sua vez, defende que a aprendizagem é compreendida como "uma mudança no comportamento da pessoa pela incorporação de novos hábitos, atitudes, conhecimentos e habilidades." Na aviação, o treinamento volta-se, ainda, para a elevação dos níveis de segurança operacional e a prevenção de acidentes. Para tanto, é preciso identificar quais são as necessidades de treinamento, a fim de que se desenvolvam e se treinem as habilidades evidenciadas.

\section{HABILIDADES TÉCNICAS E HABILIDADES NÃO TÉCNICAS DE PILOTOS}

A contratação de pilotos altamente capacitados é um desafio enfrentado por empresas aéreas em todo o mundo. Isso porque há considerável dificuldade em aferir as principais habilidades que o piloto profissional deve possuir com vistas à operação segura e eficiente da aeronave. Esta dificuldade ensejou a elaboração de estudos destinados a investigar habilidades/repertórios relevantes para uma atuação cada vez mais segura. Em 1990, a empresa aérea Lufthansa, ao lado da European Union Aviation Safety Agency (EASA) e de outras empresas aéreas, realizaram uma longa análise a fim de identificar quais seriam as habilidades mais importantes que esses profissionais deveriam possuir para operar a aeronave com segurança (LIFT AVIATION, 2018).

O intuito da pesquisa era aprimorar os treinamentos, mas acabou servindo como um guia nos processos de seleção de pilotos pelas companhias aéreas. De acordo com 
o estudo, os resultados mostraram que os pilotos devem deter duas grandes habilidades: as técnicas e as não técnicas ou comportamentais, também chamadas de Hard e Soft Skills, respectivamente (LIFT AVIATION, 2018).

Segundo Leme (2012), as habilidades técnicas referem-se a todos os conhecimentos específicos que o profissional deve dominar para o exercício de sua função. No caso dos pilotos, elas envolvem os conhecimentos em operação por instrumentos, navegação aérea, peso e balanceamento, planejamento de voo, meteorologia, domínio de outro idioma, bem como a habilidade de voar a aeronave em si, realizando manobras, pousos e decolagens, por exemplo. As habilidades técnicas são tangíveis e adquiridas dentro de salas de aula, em voos de instrução, em simuladores e por meio de livros, apostilas e outros materiais didáticos.

Já as habilidades não técnicas referem-se a comportamentos que afetam diretamente o desempenho do indivíduo e sua relação com outras pessoas, bem como a sua tomada de decisão, o comportamento de liderança e a flexibilidade de repertório (LEME, 2012). Segundo Farias (2014), a ICAO propõe que o aluno-piloto seja avaliado e analisado em nove requisitos de habilidades específicas para a operação segura e eficiente do voo, quais sejam: a aplicação de procedimentos; comunicação; gerenciamento da rota de voo da aeronave - controle manual; gerenciamento da rota de voo da aeronave - automatização; liderança e trabalho em equipe; solução de problemas e tomada de decisão; consciência situacional; gerenciamento de carga de trabalho; e gerenciamento de ameaças e erros.

De acordo com a European Cockpit Association (ECA, 2013), os pilotos devem ser capazes de desenvolver tanto as habilidades técnicas quanto as não técnicas, coordenando-se entre as duas e desempenhando, assim, sua função de forma hábil. Nesse sentido, a formação de pilotos requer uma série de habilidades singulares que podem contribuir, e muito, para o incremento da segurança de voo e das operações.

\section{OS TREINAMENTOS AERONÁUTICOS EM HABILIDADES NÃO TÉCNICAS}


Com a evolução das tecnologias, as habilidades requeridas do piloto precisaram se amoldar à nova realidade imposta pelo mercado. Há algumas décadas, eram exigidas do piloto somente três aptidões básicas, muito conhecidas na aviação: voar, navegar e comunicar, ficando o gerenciamento e monitoramento dos sistemas mais complexos a cargo dos engenheiros de voo (BRASILIO, 2012).

Contudo, com o advento dos cockpits mais automatizados e com o fim da posição do engenheiro de voo na cabine, demandaram-se dos pilotos habilidades mais amplas, as de gerenciamento de inúmeros sistemas da aeronave. As habilidades motoras até então requisitadas com muito rigor estão sendo reduzidas pelos sistemas automatizados das novas aeronaves, exigindo-se, desse modo, igual relevância entre habilidades técnicas e não técnicas (BRASILIO, 2012).

\subsection{TREINAMENTO EM GERENCIAMENTO DE RECURSOS DE EQUIPE (CRM)}

Tais constatações levaram a um consenso de que era necessária a criação de um programa de treinamento que desse ênfase a aspectos que influenciam a coordenação e o gerenciamento de recursos de tripulação. Após estudo realizado pela National Transportation Safety Board (NTSB), na década de 1970 - cujos resultados foram analisados em um artigo escrito por John K. Lauber, da Nasa, intitulado Cockpit Resource Management - criou-se o programa de mesmo nome, em português, Gerenciamento de Recursos de Cabine (Cockpit Resource Management-CRM), com a finalidade de minimizar o erro humano como fator contribuinte nas ocorrências aeronáuticas, ministrado, no início, apenas para a tripulação técnica (ANAC, 2020). Mais tarde, o termo Cockpit (Cabine) se modificou para Crew (Tripulação), onde buscava-se uma melhor coordenação dos tripulantes envolvidos com a operação da aeronave em prol da elevação da segurança operacional, atualmente também se usa o termo Corporate (Equipe) mais amplo, onde fazem parte todos os envolvidos da empresa aérea, como diretores e gestores, supervisores, tripulantes, mecânicos, dentro outros (ANAC, 2020). 
De acordo com Helmreich (2010), o treinamento de CRM visa criar situações nas quais o piloto possa colocar em prática conhecimentos teóricos sobre comunicação e gerenciamento de recursos de cabine adquiridos durante sua formação. Basicamente, o treinamento de CRM está sedimentado em torno de três fases, em que se esclarecem os conceitos iniciais, seguidos da prática e da reciclagem em CRM realizadas a cada 2 anos. No Brasil, o treinamento de CRM pode ser encontrado em escolas de aviação civil que oferecem o curso nas formas teórica e prática como complemento à formação dos pilotos, além de constar da grade curricular de cursos de Ciências Aeronáuticas e Aviação Civil.

Em suma, o treinamento de CRM visa, através do desenvolvimento de habilidades cognitivas e sociais - como liderança e cooperação, relacionamentos interpessoais, comunicação efetiva, gerenciamento de carga de trabalho e de estressores, consciência situacional, entre outras -, a utilização adequada de todos os recursos disponíveis para alcançar mais segurança e eficiência nas operações aéreas. Nesse contexto, as habilidades não técnicas trabalhadas no CRM podem ser associadas a outros treinamentos, como o Line Oriented Flight Training (LOFT), com simuladores de voo, dirigido ao desenvolvimento de habilidades técnicas e não técnicas.

\subsection{LINE ORIENTED FLIGHT TRAINING (LOFT)}

Segundo Passaglia (2016), os simuladores de voo, muito utilizados durante a Segunda Guerra Mundial para treinamento dos pilotos de combate, tinham o intuito de aprimorar habilidades técnicas nos pilotos. Contudo, com os avanços das percepções sobre os treinamentos, os simuladores de voo passaram a ser reconhecidos como um dispositivo que poderia também desenvolver nos profissionais as habilidades não técnicas, o que fez com que, nos anos 1990, esses equipamentos ganhassem novas aplicabilidades e serventias.

Nesse sentido, o LOFT, segundo o ANAC (2020), é uma capacitação em simulador de voo em que normalmente se aplica o treinamento de CRM em sua segunda fase, a da prática. Baseia-se no método da simulação de situações reais que possam 
ocorrer durante um voo, desde as rotineiras até às anormais, de emergência e de estresse. Ou seja, o LOFT projeta os mais variados cenários, fazendo com que os membros da tripulação empregue esforços de coordenação, visando sempre um desempenho satisfatório.

Segundo a Federal Aviation Administration (FAA, 2004), o objetivo geral do LOFT é melhorar a performance dos pilotos por meio da combinação do CRM e das habilidades técnicas, usando-se de cenários simulados. Esses cenários devem durar o suficiente para que as características da tripulação se tornem evidentes e exigir que as habilidades de CRM sejam dadas em resposta a circunstâncias específicas. Contudo, ainda se faz necessário o aprimoramento de habilidades não técnicas mais amplas mediante outros treinamentos disponíveis, de modo a contribuir com a conjuntura de aptidões dos pilotos (PASSAGLIA, 2016).

\subsection{TREINAMENTO EM HABILIDADES SOCIAIS (THS)}

As relações interpessoais são inerentes à vida em sociedade. O homem se relaciona com outros indivíduos em praticamente todas as esferas, ao longo de sua existência. Para que essa interação ocorra de maneira fluida, o desenvolvimento de habilidades sociais é necessário, visto que as interações sociais são fundamentais para atividade humana. Tendo em vista que a aviação envolve interações entre indivíduos, seja dentro da cabine de uma aeronave ou em outras instâncias do modal aéreo, as habilidades sociais igualmente tornam-se indispensáveis ao meio aeronáutico.

Com isso, para desenvolver tais habilidades nos indivíduos tem-se o Treinamento de Habilidades Sociais (THS). De acordo com Murta (2005), o THS iniciou-se na Inglaterra na década de 1970, com estudos da Universidade de Oxford, recebendo também contribuições da área de treinamento assertivo, em andamento na mesma época nos Estados Unidos, além de ter sido impulsionado por inúmeras publicações.

No THS adotam-se diferentes estratégias comportamentais que têm como objetivo aperfeiçoar as competências sociais do indivíduo. Isto porque os déficits em 
habilidades sociais podem gerar conflitos nos relacionamentos interpessoais, bem como baixa qualidade de vida, afetando tanto a vida pessoal como a profissional das pessoas (PORTELLA; PADULA, 2011). Entre as habilidades sociais, pode-se pontuar, por exemplo, a comunicação de ideias de maneira clara e eficaz; a apresentação de repertórios de civilidade, assertividade e empatia; e a capacidade de manejar conflitos e solucionar problemas interpessoais (DEL PRETTE; DEL PRETTE, 2019).

Vale destacar, nesse contexto, que o treinamento de CRM, já comentado, se correlaciona com o THS principalmente no quesito comunicação eficaz. O THS, nesse sentido, aborda aspectos como manejo de ansiedade e de respostas emocionais, habilidades para manter uma conversação clara e eficiente, melhores formas de se expressar, estratégias para tomadas de decisão, habilidades de colocação de opinião, habilidades de lidar com ansiedade e raiva de outras pessoas, entre outros (MURTA, 2005). O THS e o CRM seguem, portanto, as mesmas linhas de ensinamentos, com a utilização da encenação - role playing.

O THS, contudo, pode ser considerado mais amplo que o CRM por abarcar, além dos aspectos comuns aos dois, estratégias como, por exemplo, o uso da respiração diafragmática para redução de respostas emocionais frente a estímulos estressores, de um modo geral. Sendo assim, o THS é capaz de auxiliar os pilotos frente a situações adversas, como de emergências, que ocasionam níveis elevados de ansiedade e estresse (PUREZA, 2012).

\subsection{SISTEMA NOTECHS}

O sistema NOTECHS, nome representado pela sigla de Non Technical Skills (Habilidades Não Técnicas), foi criado em 1998 como uma metodologia de avaliação das habilidades não técnicas nos pilotos, tendo como base indicadores comportamentais. O sistema funciona como um guia voltado a instrutores de voo e inspetores de aviação civil sobre o modo como devem avaliar a proficiência de pilotos, de acordo com os regulamentos europeus (ESCUDEIRO, 2012). Seu principal objetivo é identificar a necessidade de treinamentos em habilidades não técnicas nos pilotos, 
especialmente aquelas relacionadas ao CRM, baseado em comportamentos observáveis.

O sistema NOTECHS abrange quatro categorias principais: cooperação; liderança e habilidades gerenciais; consciência situacional; e tomada de decisão. As duas primeiras categorias citadas (cooperação; liderança e gerenciamento) configuram habilidades sociais; já as duas últimas (consciência situacional e tomada de decisão) constituem-se habilidades cognitivas. Cada uma delas contém elementos e marcadores de comportamentos que evidenciam as habilidades não técnicas mais relevantes aos pilotos profissionais e que, consequentemente, devem ser observadas, bem como treinadas e avaliadas durante a capacitação. Como exemplo, dentro da categoria consciência situacional, há os elementos: consciência dos sistemas da aeronave, do ambiente externo, e do tempo (FLIN at al., 2003).

Em suma, o sistema NOTECHS trabalha em prol da redução da subjetividade no momento da avaliação de desempenho dos pilotos nas habilidades não técnicas ligadas ao CRM e para que os objetivos do treinamento e os resultados das avaliações funcionem em conjunto com vistas à melhoria contínua dos padrões de treinamento de pessoal, tendo como foco último a segurança de voo.

\subsection{EVIDENCE-BASED TRAINING (EBT)}

O Evidence-Based Training (EBT) ou Treinamento Baseado em Evidências surgiu de um consenso de toda a comunidade aeronáutica - especialistas em treinamento, associações de pilotos, autoridades reguladoras, operadores aéreos e fabricantes de aeronaves - de que era necessário reduzir as taxas de acidentes e incidentes aeronáuticos fatais de forma mais eficiente ou diferenciada. Sendo assim, criou-se um método de treinamento e avaliação que se baseia em dados operacionais e se caracteriza pelo desenvolvimento e avaliação da capacidade geral do piloto numa série de competências-chave, e não pela mensuração do desempenho em cenários ou manobras individuais, como ocorria até então (ICAO, 2013). 
O EBT, assim como os demais ora debatidos, tem o propósito de identificar, desenvolver e avaliar habilidades relevantes para que os pilotos operem com segurança e eficiência em um ambiente de transporte aéreo comercial. No entanto, ele traz dois importantes diferenciais em relação a outros treinamentos: as competências-chave e as evidências. As competências-chave são baseadas em situações adversas nas quais o desempenho do piloto foi excelente. Esse comportamento passa a compor então os indicadores de desempenho (ou indicadores comportamentais). Estas competências são observáveis e mensuráveis e referem-se a repertórios que o piloto precisa apresentar, adquirir ou desenvolver para operar a aeronave com segurança. Já as evidências são os resultados das análises de dados globais das operações - extraídos do Line Operations Safety Audit (LOSA) e do Flight Data Analysis (FDA) - ou de dados coletados em treinamento, acidentes e incidentes aeronáuticos (ICAO, 2013).

Com isso, por meio das competências-chave e das evidências levantadas, verifica-se a necessidade de realização do treinamento, que é feito em simulador de voo de alta acuracidade, os chamados Full-Flight Simulators, para que os pilotos gerenciem as mais relevantes ameaças e cenários baseados nas informações coletadas nas operações. Em síntese, para que esse modelo de treinamento funcione de maneira eficaz, é crucial o levantamento de um grande conjunto de dados, incluindo pesquisas do comportamento dos pilotos durante o voo, relatórios de segurança, observações e dados dos voos. O EBT, desse modo, consiste em potente ferramenta para adaptação em programas de treinamento de pilotos, principalmente dentro de empresas aéreas, para que se treine e desenvolva as habilidades evidenciadas (SOUZA, 2017).

\subsection{MULTI-CREW PILOT LICENSE (MPL)}

A Multi-Crew Pilot License, ou Licença de Tripulação Múltipla (MPL), foi adotada pela ICAO em 2006, como uma emenda ao Anexo 1, que trata de licença de pessoal. Tal emenda, veio ao encontro das necessidades de evolução nos treinamentos de pilotos (SKYBRARY, 2020). 
A MPL é uma modalidade de licença que tem como objetivo a otimização e a melhora da formação para pilotos de linha aérea e, como base, o desenvolvimento de habilidades. Com isso, os pilotos passam a ter uma licença que Ihes permite conduzir aeronaves com um alto grau de eficiência e segurança e que satisfaça o treinamento necessário a uma linha aérea específica de forma mais direcionada, ou seja, o foco é a formação de pilotos de aeronaves comerciais (FAY; FONTES, 2016).

Para tanto, segundo a ICAO (2011), o candidato deverá possuir o Certificado Médico Aeronáutico (CMA) de primeira classe (Piloto de Linha Aérea); realizar, com aproveitamento máximo, os cursos teóricos, bem como as avaliações propostas; executar 240 horas de voo, sendo que a grande mudança é que, dessas 240 horas, apenas 35 são em aeronave real, enquanto as restantes ocorrem em simuladores de voo.

Pode-se afirmar, portanto, que o desenvolvimento de suas habilidades técnicas e não técnicas aconteceria, dentro do contexto das licenças, como uma evolução que parte da licença de piloto privado até a de piloto de linha aérea, estágio em que se alcançariam os requisitos e habilidades necessárias para se voar aeronaves de tripulação múltipla. Portanto, a MPL substituiria, segundo Fay e Fontes (2016), todo o processo de treinamento atualmente exigido para PP, PC e PLA. Contudo, a MPL tem sofrido certa resistência por parte da comunidade aeronáutica. Segundo Schroeder e Harms (2007), um equívoco comum sobre o programa é de que ele teria surgido como contramedida à escassez de pilotos na Ásia, especialmente na China e na Índia, onde as ferramentas de qualificação de pilotos não mantêm o mesmo ritmo de qualificação da atual indústria da aviação.

Segundo a IATA (2015), até o final do ano de 2015 existiam cerca de 31 programas de MPL homologados no mundo. Algumas empresas aéreas, como Etihad, Air China, Swiss e Qatar Airways, já contam com esse tipo de treinamento. Contudo, mesmo a licença de MPL já sendo adotada em alguns países, no Brasil não há qualquer curso homologado ou em processo de homologação. 
Segundo Ruff-Stahl (2016), o fator contribuinte para a ausência de centros de treinamentos que utilizem do MPL no Brasil é a dificuldade de se gerenciar um centro de treinamento próprio, no caso das companhias aéreas. Permanece, portanto, o processo de contratação habitual por meio da seleção de profissionais já capacitados por conta própria em escolas ou faculdades, apenas sendo realizado na empresa o Type Rating, que é a certificação para pilotar um determinado tipo de aeronave que requer treinamento adicional além do escopo da licença inicial e do treinamento de classe (PASSAGLIA, 2016).

Portanto, independentemente das divergências em torno da MPL no meio aeronáutico, fato é que ela representa o primeiro grande conceito de mudança nos padrões atuais e antigos de treinamento de pilotos de linhas aéreas. Com seu enfoque baseado no desenvolvimento de habilidades, se bem implementada, pode melhorar e otimizar a formação de pilotos profissionais no mundo.

\section{CONSIDERAÇÕES FINAIS}

Em vista dos argumentos apresentados, verificou-se que a atuação dos pilotos exerce grande influência na segurança do voo, principalmente em situações adversas que envolvam estresse e alta carga de trabalho, como as emergências. Contudo, os fatores operacionais e humanos ainda são os grandes responsáveis, no cenário mundial da aviação, pelos acidentes e incidentes aeronáuticos. Dentre os fatores mais mencionados e apontados como falhas humanas destacam-se o julgamento de pilotagem, a tomada de decisão e a comunicação.

Com base nessa prerrogativa, o treinamento e o desenvolvimento de habilidades não técnicas nos pilotos durante a sua formação são de fundamental importância, em especial para a prevenção de ocorrências aeronáuticas, pois a formação e o treinamento continuado voltados também para essas habilidades funcionam como barreiras a ocorrências dos acidentes, quebrando, assim, a cadeia de eventos que levaria ao acidente. 
Dito de outro modo, quanto mais habilidades os profissionais tiverem, melhor será o seu desempenho. Certamente, a combinação de habilidades bem desenvolvidas é grande valia no momento de uma tomada de decisão ou na realização de um julgamento de pilotagem, bem como para uma comunicação eficiente com os outros tripulantes. Durante uma emergência, por exemplo, essa combinação de repertórios pode ser decisiva para o sucesso ou fracasso da situação, e, de efeito, para a salvar ou não vidas a bordo da aeronave.

Um exemplo significativo da relevância da combinação de repertórios técnicos e não técnicos é o ocorrido em janeiro de 2009, quando o comandante Sully realizou um pouso no rio Hudson, em Nova lorque, com o voo 1549. Seu correto julgamento, sua tomada de decisão assertiva, bem como sua comunicação eficaz o levaram a realizar um pouso com êxito no meio do rio. Sully afirma que o fator que o levou ao pouso com sucesso foi a combinação de suas experiências, treinamentos e habilidades desenvolvidas desde o seu primeiro voo, alcançada por meio da contribuição de inúmeras pessoas, instruções, cursos e formação durante sua vida (SULLENBERGER; ZASLOW, 2016). Indubitavelmente, os repertórios adquiridos ao longo dos anos por Sully envolviam tanto habilidades técnicas de manejo da aeronave, quanto habilidades não técnicas, e, diante de uma situação de emergência, o experiente piloto lançou mão de tais conhecimentos para evitar um acidente.

Os treinamentos de CRM, LOFT, THS e EBT, bem como a licença MPL e o sistema NOTECHS visam, sem embargo de dúvidas, aumentar a segurança da atividade aérea ao aprimorar a formação dos pilotos, que deve extrapolar as habilidades técnicas. Contudo, ainda são poucas as instituições no mundo que oferecem esses treinamentos, e no Brasil tais instituições são em número ainda menor. Soma-se a este obstáculo o alto custo desses treinamentos, o que dificulta, mesmo para os mais interessados, o desenvolvimento de habilidades não técnicas.

Nesse sentido, é imprescindível que haja maior incremento e divulgação dos treinamentos disponíveis para que o acesso a eles de fato ocorra, seja no ambiente das escolas de aviação e em cursos superiores de formação de pilotos. Além disso, é 
necessário que as agências reguladoras criem normas que imponham a implementação dessa formação na grade curricular dos cursos de formação de pilotos, sejam eles técnicos (em escolas de aviação e centros de treinamento) ou superiores (nas universidades), como dito, provendo disciplinas teóricas e práticas que desenvolvam nos alunos tais habilidades.

Sugere-se, nesse sentido, que sejam empreendidos novos estudos no meio aeronáutico e acadêmico para que se levantem as melhores formas de viabilizar sua implementação nos ambientes mencionados. Por fim, espera-se que este e outros trabalhos possam sinalizar a importância do treinamento de habilidades não técnicas para a formação mais completa dos pilotos com vistas, em última análise, à diminuição nos números de acidentes que tenham o desempenho humano como fator contribuinte.

\section{REFERÊNCIAS}

ANDRADE, J. E.; CASTRO, G. A. Treinamento e Desenvolvimento: reflexões sobre suas pesquisas cientificas, 1996. Disponível em: $<$ https://repositorio.unb.br/bitstream/10482/1123/1/ARTIGO_Treinamento_Desenvolv imento_Pesquisas_Cient\%c3\%adficas.pdf>. Acesso em: 14 set. 2020.

BARATA, J. M. M.; NEVES, F. M. S. P. The history of Aviation Education and Training. Disponível em: $<$ https://www.scirp.org/pdf/OJAppS_2017050510013401.pdf>. Acesso em: 4 set. 2020.

BRASILIO, G. B. O curso superior em ciências aeronáuticas como requisito para a obtenção de licenças de pilotagem: uma medida proativa na prevenção de acidentes. 2012. 83f. Dissertação (Mestrado em Engenharia Aeronáutica e Mecânica) - Instituto Tecnológico de Aeronáutica, São José dos Campos/SP. 
CARNEIRO, R. Duelo: Irmãos Wright X Santos Dumont. Super Interessante, Editora Abril, 2016. Disponível em: <https://super.abril.com.br/mundo-estranho/duelo-irmaoswright-x-santos-dumont/>. Acesso em: 3 set. 2020.

CASSIANO, S. K. Learning to Fly: o papel da aprendizagem na segurança operacional, 2017. Revista Conexão Sipaer, v. 8, n. 3, p. 2-18.

CENTRO DE INVESTIGAÇÃO E PREVENÇÃO DE ACIDENTES AERONÁUTICOS (CENIPA). Aviões: Sumário estatístico 2008-2017. 2018. Disponível em: $<$ http://sistema.cenipa.aer.mil.br/cenipa/paginas/arquivos/avioes_sumario_estatistico .pdf>. Acesso em: 25 set. 2020.

Painel SIPAER, 2020. Disponível em: $<$ http://painelsipaer.cenipa.aer.mil.br/QvAJAXZfc/opendoc.htm?document=SIGAER \%2Fgia\%2Fqvw\%2Fpainel_sipaer.qvw\&host=QVS\%40cirros3137\&anonymous=true>. Acesso em: 25 set. 2020.

CHIAVENATO, I. Gestão de pessoas: o novo papel da gestão do talento humano. 5 ed. São Paulo: Atlas, 2020.

CORDEIRO, T. Os primórdios da aviação. Aventuras na História, 2006. Disponível em: <https://aventurasnahistoria.uol.com.br/noticias/acervo/primordios-aviacao434923.phtml>. Acesso em: 4 set. 2020.

DEL PRetTe, A.; DEL PRetTe, Z. A. P. Competência Social e Habilidades Sociais: Manual teórico-prático. 3 ed. Petrópolis: Editora Vozes, 2019.

AGÊNCIA NACIONAL DE AVIAÇÃO CIVIL (ANAC). Instrução de Aviação Civil 00010A: Treinamento de gerenciamento de recursos de equipes. 2020. Disponível em: Acesso em:< https://www.anac.gov.br/assuntos/legislacao/legislacao-1/boletimde-pessoal/2020/24/anexo-ii-is-00-010a.pdf>. Acesso em: 13 set. 2020. 
ESCUDEIRO, M. L. Notechs: um modelo de avaliação das habilidades não técnicas através de indicadores comportamentais, 2012. Disponível em: <file:///Users/joaopedrolimaacosta/Downloads/145-1036-2-PB\%20(1).pdf>. Acesso em: 13 set. 2020.

EUROPEAN COCKPIT ASSOCIATION. Pilot Training Compass: back to the future. 2013. Disponível em: <https://www.eurocockpit.be/sites/default/files/eca_pilot_training _compass_back_to_the_future_13_0228.pdf>. Acesso em: 13 set. 2020.

FAY,

C.

M.;

FONTES,

R.

de

S.

O papel do Aeroclube do Brasil na construção de uma política nacional de aviação brasileira (1911-1972). 2016. Disponível em: $<$ https://www.scielo.br/scielo.php?pid=S010190742017000100505\&script=sci_arttext>. Acesso em: 3 set. 2020.

Formação por competência: discutindo a formação de pilotos no Brasil, 2016. Disponível em: <https://www.scielo.br/scielo.php?script=sci_arttext\&pid=S0100$15742016000401148 \&$ Ing=pt\&tIng=pt>. Acesso em: 10 set. 2020.

FARIAS, F. L. Parâmetros para avaliação de competências subjetivas na formação do piloto comercial: avião. 2014. 39f. Especialização (Monografia de MBA em Inteligência de Negócios) - Universidade Federal do Paraná, Curitiba/PR.

FEDERAL AVIATION AND ADMINISTRATION (FAA). Advisory circular. Line Operational Simulations: Line Oriented Flight Training, 2004. Disponível em: <https://www.faa.gov/documentLibrary/media/Advisory_Circular/AC\%2012035C.pdf $>$. Acesso em: 13 set. 2020.

FLIN, R. et al. Development of the NOTECHS (non-technical skills) system for assessing pilots' CRM skills. Human Factors and Aerospace Safety, v. 3, p. 97-120, 2003. 
HELMREICH, R. L.; ANCA, J. M. Crew resource management. London: Elsevier, 2010. Disponível em: <https://www.academia.edu/8655784/CREW_RESOURCE_ MANAGEMENT>. Acesso em: 14 set. 2020.

INTERNATIONAL AIR TRANSPORT ASSOCIATION (IATA). Guidance material and best practices for MPL implementation, $2^{\text {nd }}$ edition, 2015. Disponível em: $<$ https://www.iata.org/contentassets/c0f61fc821dc4f62bb6441d7abedb076/guidancematerial-and-best-practices-for-mpl-implementation.pdf>. Acesso em: 12 set. 2020.

INTERNATIONAL CIVIL AVIATION ORGANIZATION (ICAO). Manual of EvidenceBased Training, $3^{\text {rd }}$ edition. Montreal, 2013.

. International Standards and Recommended Practices: Innex 1 Personnel Licensing, $2011 . \quad$ Disponível em: <http://cockpitdata.com/Software/ICAO\%20Annex\%201>. Acesso em: 2 set. 2020.

KAPERAVICZUS, A. F.; CAVENAGHI, A. J. As memórias da aviação e a hospitalidade no Brasil, 2018. Disponível em: <https://periodicos.ufjf.br/index.php/abet/article/view/3194>. Acesso em: 3 set. 2020.

LEME, R. Avaliação de desempenho com foco em competência: a base para remuneração por competências, 3 ed. Rio de Janeiro: Editora Qualitymark, 2012.

LIFT Aviation Brasil. Quais habilidades as companhias aéreas realmente buscam em pilotos? 2018. Disponível em: <https://liftaviation.com.br/posts/quais-ashabilidades-que-as-companhias-aereas-realmente-buscam-em-pilotos/>. Acesso em: 12 set. 2020.

MILKOVICH, G. T.; BOUDREAU, J. W. Administração de Recursos Humanos. São Paulo: Atlas, 2010.

MURTA, S. G. Aplicações do treinamento em habilidades sociais: análise da produção nacional. Psicologia: Reflexão e Crítica, v. 18, n. 2, p. 283-291, 2005. 
MULTI-CREW PILOT LICENCE (MPL). 2020. Disponível em: $<$ https://www.skybrary.aero/index.php/Multi-crew_Pilot_Licence_(MPL)>. Acesso em: 14 set. 2020.

NATIONAL TRANSPORTATION SAFETY BOARD (NTSB). Annual Review of Aircraft Accident Data, 2010. Disponível em: <http://libraryonline.erau.edu/onlinefull-text/ntsb/aircraft-accident-data/ARC10-01.pdf>. Acesso em: 24 set. 2020.

PASSAGLIA, D. P. As habilidades não técnicas na formação inicial de pilotos de avião. 2016. Trabalho de Conclusão de Curso (Bacharelado em Ciências Aeronáuticas) - Pontifícia Universidade Católica de Goiás, Goiânia/GO.

PORTO, N. M. L. Um resumo da história do transporte aéreo. 1 ed. Goiânia. 2015. PORTELLA, M.; PADULA, C. Estratégias de THS: Treinamento em Habilidades Sociais. 1 ed. Rio de Janeiro: CPFAF-RJ, 2011.

PUREZA, J. da R. et al. Treinamento de habilidades sociais em universitários: uma proposta de intervenção. Revista Brasileira de Terapias Cognitivas, v. 8, n. 1, p. 29, 2012.

REGINATTO, A. P. Equipes campeãs: potencializando o desempenho de sua equipe. 2 ed. Porto Alegre: SEBRAE, 2004.

REASON, J. Human Error. 1 ed. Cambridge: University Printing House, 1990.

RONDON, M. H.; CAPANEMA, C. F.; FONTES, Rejane S. A interação homemmáquina nas aeronaves tecnologicamente avançadas: a transformação de um paradigma, 2014.

Disponível em: <https://www.academia.edu/23364999/A_intera\%C3\%A7\%C3\%A3o_homem _m\%C3\%A1quina_nas_aeronaves_tecnologicamente_avan\%C3\%A7adas_a_transf orma\%C3\%A7\%C3\%A30_de_um_paradigma>. Acesso em: 2 set. 2020. 
RUFF-STAHL, H.-J. K. et al. Measuring CRM aptitude: is NOTECHS a suitable tool for pilot selection? International Journal of Aviation, Aeronautics and Aerospace, v. 3, n. 3, p. 4, 2016.

SCHROEDER, C.; HARMS, D. MPL represents a state-of-the-art ab initio pilot training programme. The ICAO Journal, v. 62, n. 3, p. 15-16, 2007. Disponível em: $<$ https://www.icao.int/publications/journalsreports/2007/6203_en.pdf>. Acesso em: 10 set. 2020.

SOUZA, C. E. Aplicabilidade do treinamento baseado em evidências na aviação civil. 2017. 47f. Monografia (Graduação em Ciências Aeronáuticas) - Universidade do Sul de Santa Catarina, Palhoça - SC.

SULLENBERGER, C.; ZASLOW, J. Sully: o herói do rio Hudson. 1 ed. Rio de Janeiro: Intrínseca, 2016.

Enviado: Março, 2021.

Aprovado: Maio, 2021. 